\title{
GIS applications in urban management
}

\author{
Anh Tai Nguyen ${ }^{1, *}$, and Huu Si Dao ${ }^{1}$ \\ ${ }^{1}$ University of Architecture Ho Chi Minh City, 196 Pasteur Street, Ward 6, District 3, Ho Chi Minh \\ City, Vietnam
}

\begin{abstract}
The urban development management is a complex science including many different fields in which scheming management plays a vital role. How to make the process of urbanization develop stable? Most of the departments of urban management may use drawing software to keep scheming/planning data under control, attributive information is thought to be particularly treated or directly noted in drawing file. With the aforementioned facts, the management of urban plan is simplified and the urban planning managers can reduce their labor, as well as their time. Climate change is increasingly complex and unpredictable worldwide. The consequence of global warming is the rise in sea level that caused more severe flooding. Vietnam is one of the countries severely affected by this process. In this paper, the authors aim to use the opportunities offered by GIS analysis of mapping flood warning service for flood protection, rescue, and traffic, to provide the residents with the forecast changes about the route they have chosen to move through flood zone, and to study the functional process of planning management model applying GIS technology to support the management of zoning plan.
\end{abstract}

\section{Introduction}

At present, the issue of urban planning management in Vietnam in general and in Ho Chi Minh City in particular is concerned by management levels and people. The issue of urban planning management affects not onle on an individual or a part but also on $t$ on many societies deeply, and closely related to the process of economic and cultural development... of Ho Chi Minh City and in Vietnam as well. So far, for the management and the executives, decision makers in urban planning have encountered many difficulties. Because they have not really got a tool that allows quick reference and processing, good information processing system related, leading to the process of managing urban planning and development of construction is still limited. Make the process of urbanization more complex.

Studying a suitable model in the application of GIS (Geographic Information System) model into the planning management problem in general and detailed zoning planning, detailed planning in particular. To create one of the useful auxiliary tools for searching and processing information systems related to urban planning and construction development. This will allow managers and people who work in building planning to have the tools to make decisions and execute them more quickly, accurately and efficiently.

\footnotetext{
*Corresponding author: natai1969@yahoo.com
} 
Today, climate change is a very serious global problem concerned to all countries. The consequences of this phenomenon is the warming of the Earth's temperature and the rise of sea levels. Vietnam is also one of the countries affected by rising sea levels most. The Ministry of Natural Resources and Environment in collaboration with the Intergovernmental Panel on Climate Change (IPCC) and on the basis of United Nations Framework Convention on Climate Change (United Nations Framework Convention on Climate Change, the UNFCCC or the FCCC) introduced "Climate change and sea level rise scenarios in 2012". Thus, the problem of flood mapping in HCMC is becoming more urgent than ever. If this map is developed, it will help urban management and planning to help people choose specific routes through the wetlands.

\section{GIS application in the establishment of early warning map in ho chi minh city}

\subsection{Overview}

According to this scenario, when the sea level rises by 1 meter, the result of the risk of submergence in the sea level shows that if the sea level rises by 1 meter, about $39 \%$ of the Mekong river delta area, over 10\% In the Red River Delta and Quang Ninh, over $2.5 \%$ of the central coastal provinces are inundated. The risk of flooding in Ho Chi Minh City is over 20\% (Source: Climate change scenarios, sea level rise for Vietnam - Ministry of Natural Resources and Environment 2012).

According to professional agencies, flooding situation in Ho Chi Minh City is developing abnormally. Accordingly, since 2005 the water has been continuously flooded. At the point of Phu An sewer, in the current high tides, there is a water level rise to $1.68 \mathrm{~m}$.

Meanwhile, about $60 \%$ of the whole area of Ho Chi Minh City is lower than the tide of 1.5 meters. This leads to difficulties in securing the role of the drainage system, if not in combination with large-scale irrigation schemes and projects (by the Ministry of Agriculture and Rural Development of Vietnam) deployed in Ho Chi Minh City as well as the whole South West. (Source: http: //www.phongchonglutbaotphom.gov.vn/?id=48\&cid=5633).

In the first six months of 2012, the tidal inundation was improved over the same period in 2009, 2010 and 2011: 03 floods were seriously handled (Phan Dinh Phung, Nguyen Thi Thap and Binh Quoi streets); Two flooding points (Ngo Tat To Street and Bui Huu Nghia Street) are being processed.

There are agencies in the world that have formed flood maps and provided information on floods to residents on the mass media and on the Internet, including sites such as: http: // www.ncfloodmaps.com of the North Carolina Flood Mapping Program, or in UK http://apps.environment-agency.gov.uk; or in Southeast Asia, the Philippines has put the issue of mapping 3D flood warning: the first area to be mapped 3D is Cagayan De Oro, one of the Philippines' most disaster-prone cities with 6 months implementation. (Http://vnsc.org.vn/en/news/Ung-dung-Cong-nghe-Vu-tru/Philippines-xay-dung-ban-do-lulut-3D-264/).

The remaining major cities will be 3D mapped in the near future.

In Vietnam, the local authorities have also set up flood warning information systems, such as Quang Nam province, to develop a web-based flood information system that supports the prevention command. Floods were made with the participation of experts from the Institute of Environment and Resources, Vietnam National University. Ho Chi Minh City, Center for Meteorology and Hydrology in Quang Nam and the Institute of Meteorology, Hydrology and Environment. 
The E-Flood model proposed in this work is based on the WebGIS platform, which is a database-driven integration system, which results in running a map showing flooding and flooding in the basin. E-Flood based flood management software based on WebGIS technology ((FLOOD management software based on WebGIS technology for Quang Nam province - applied for Quang Nam) initially applied to Quang Nam with interactive analysis tools and map technology, Online Tools This will create favorable conditions for coping and mitigating damages caused by floods. (Source: http://quangnam.kttvttb.vn/)

Binh Dinh has also decided to set up flood maps to help prevent floods, especially after the historic floods in 2013. (http://www.baomoi.com/Binh-Dinh- Lap-ban-do-ngap-lut / 144 / 14254581.epi). Thus, the problem of flood mapping in HCMC has become more urgent than before. If this map is developed, the urban management and planning will help people choose specific routes through the floodplain.

\subsection{Study area}

The area of Thanh Da and Binh Quoi streets in 27 and 28 Binh Thanh, this is the place that is nicknamed inundated city.

In the morning of 6-12-2013, lots of houses in Thanh Da, Binh Thanh District, Ho Chi Minh City were submerged to the knees, the river flooded massively into the first floor buildings. As noted, beside the bank of the section in, Binh Thanh District still has a stretch of embankment has not been completely constructed. Construction materials such as piles, earth, and stone ... are lying on the shore. The construction unit used a sack to block the embankment. (Source: Tuoi tre Online).

\subsection{Research Methods}

The research steps, processes and products are shown in the schema in Figure 1[6].

The collected data includes topographic maps of the study area of 1: 2000, hydrological forecasts of the South meteorological and hydrological station, including the alarm classification at Phu An hydrological station On the Saigon River near the study area.

This study uses the Engage 3D Professional software package based on MapInfo-GIS.

This software package allows the establishment of 3D models of terrestrial and terrestrial DEM models as well as spatial 3D modeling of this DEM model. From 2D topographic maps, 3D models are constructed for the content layers of the map such as terrain of terrain, buildings (houses, electric poles, etc.), roads, other contents in accordance with actual altitude.

\subsection{Result}

In Figure 2 part of the map in Thanh Da area, Binh Quoi in which the house is classified according to building materials and roof form.

Based on the collected hydrology data, Engage 3D's DEM 3D analysis function was used to establish the wetland zoning for each level of hydrological alarm at Phu An station.

Table 1. The flood level classification table at Phu An station on the Saigon River.

\begin{tabular}{|l|l|l|c|c|c|}
\hline \multirow{2}{*}{ No } & \multirow{2}{*}{ River } & \multirow{2}{*}{ Station } & \multicolumn{3}{|c|}{ Water level corresponds to alarm level (m) } \\
\cline { 4 - 6 } & & & I & II & III \\
\hline 1 & Saigon & Phu An & 1,3 & 1,4 & 1,5 \\
\hline
\end{tabular}


The water level forecast at Phu An station from January 3, 2014 to May 05, 2014 issued by the City Department of Flood and Storm Control, surpasses alarm 3.

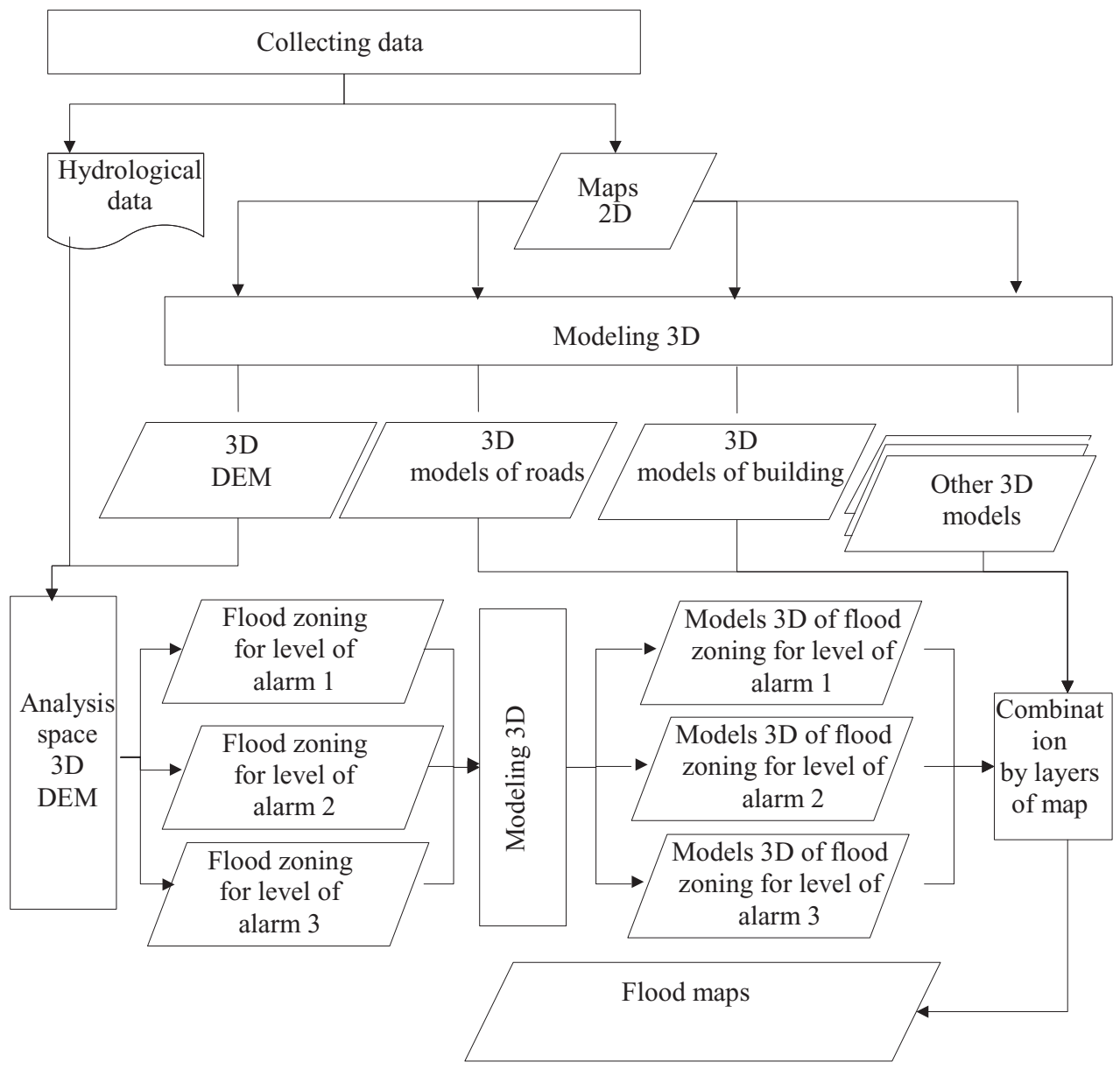

Fig. 1. Schema of the process of establishing a 3D map of flooded areas by tide.

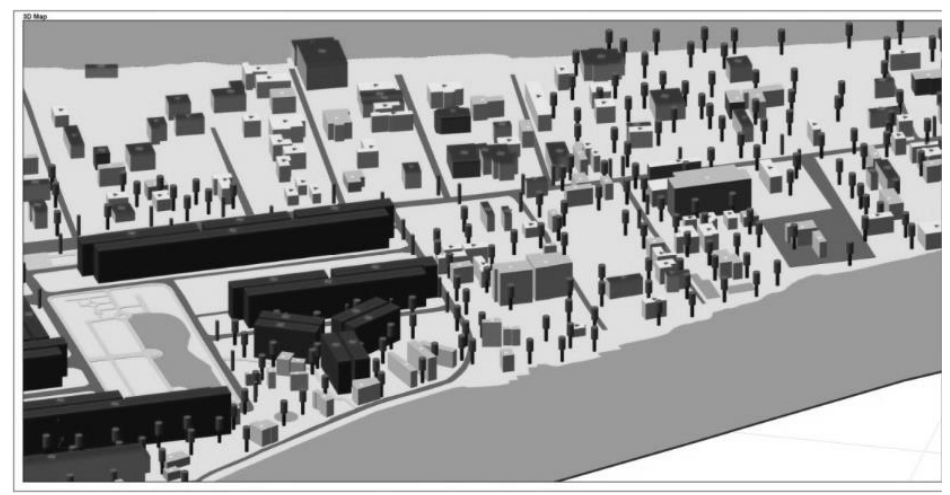

Fig. 2. Part of the map in area Thanh Da Binh Quoi, Ho Chi Minh City. 
Figure 3 shows some 3D map layers such as floodplains, houses, roads, vegetation, and so on. There are some flooded sections below the water level.
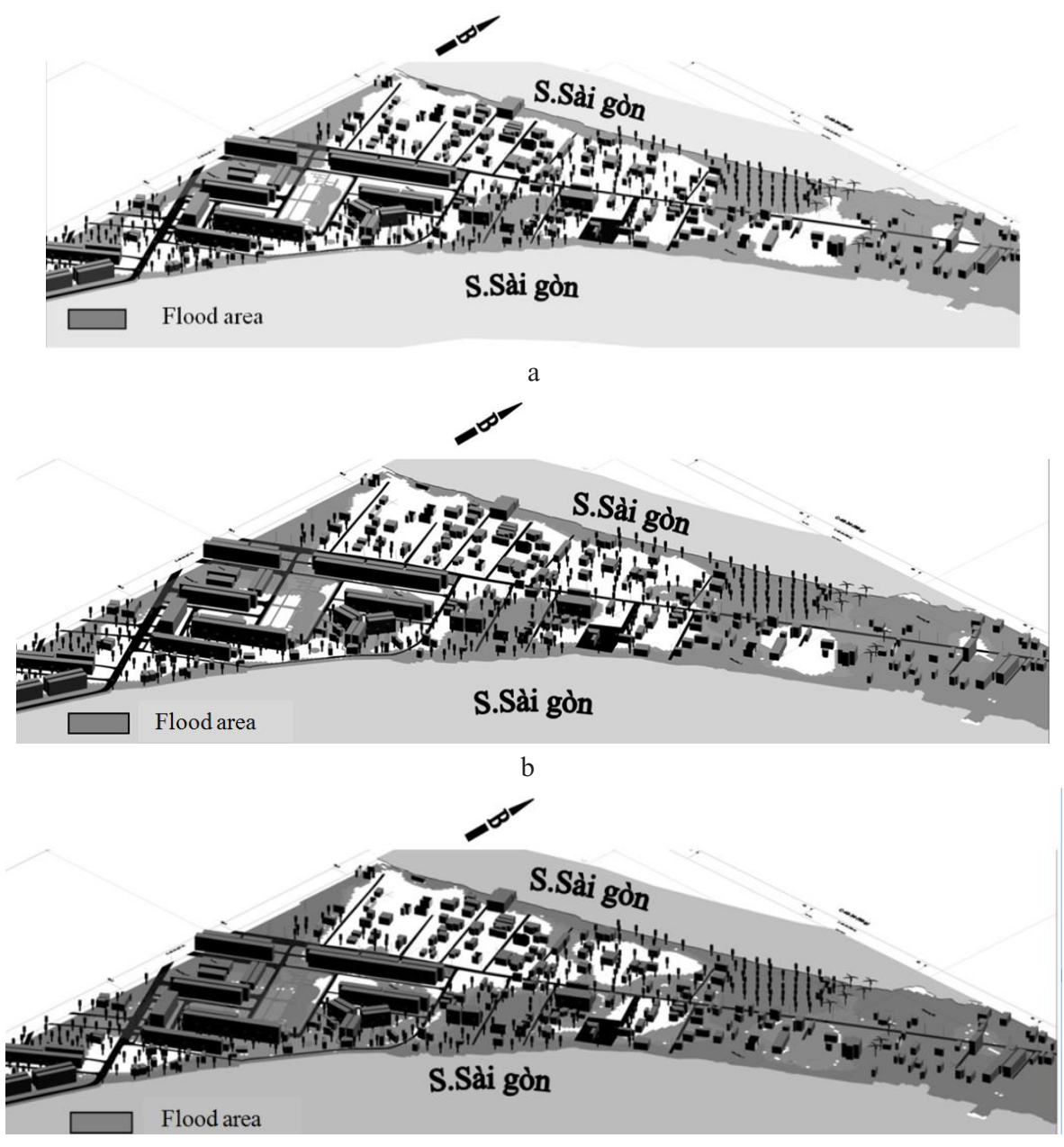

c

Fig. 3. Forecast flood 3D maps: Level 1 (a), Level 2 (b), Level 3 (c).

This corresponds to the current flood situation on October 9, 11, 10, 2014, which the media have reported and some images are shown in Figure 4 to demonstrate the suitability of map with reality. 

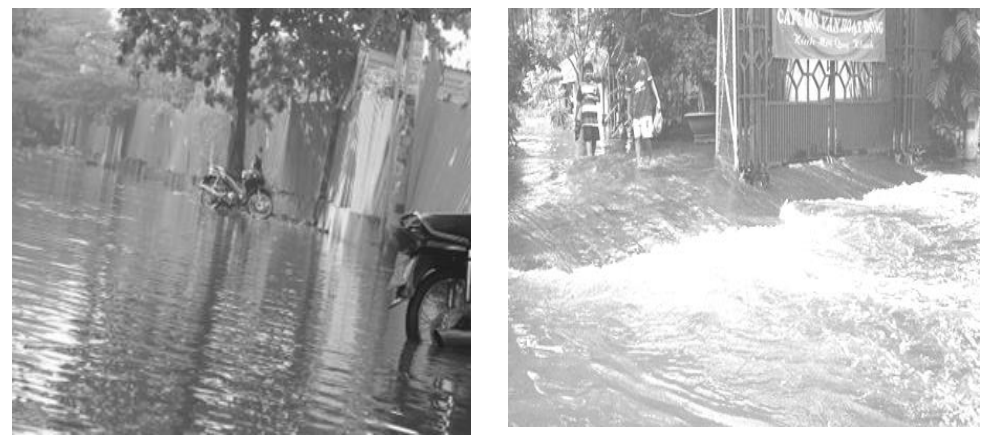

Fig. 4. Photos on 11-10-2014 in the study area (Internet source).

In addition, the Engage 3D software package allows the construction of Video Clip Field observations from above to give us an overview of the situation of flooding and floods from which to plan rescue, rescue and relief in flood area.

The MapInfo study and the Engage 3D software package showed good results in the development of 3D maps and other thematic maps, including the floodplain partition map. At present, in HCMC and most parts of the country, 2D maps are covered, which will be the source material for the $3 \mathrm{D}$ map. This process is quicker and less expensive than measuring and collecting new data in the field.

\section{GIS application model supporting the management of planning information}

\subsection{Overview}

Building a GIS application model supporting the management of planning information for functional zones in District 2 and urban management in Ho Chi Minh City, develop the integrated application modules on ESRI's ArcGIS Desktop software for the management of planning information for functional zones within the district to meet the requirements of employees. The management of planning in the following aspects:

- function for each site;

- Indicators on population, land use, technical infrastructure for each zone;

- Social infrastructure

Thesis paper is implemented with the following methods:

$\square$ Methods of collection, analysis and synthesis:

Collecting, analyzing and synthesizing related legal documents and documents

Planning data and planning information management process of the state management units

Analysis method, system design:

- Analysis, selection of application software technology, database management system and GIS technology

- Analysis of professional process of planning information management division functional district

- Design GIS database management information planning zoning function

- Analyze the design of the GIS application information management module planning subdivision function.

Research situation in the world, for countries with developed economies and science, the application of GIS in many fields of social life has been widely applied and has brought about 
many successes. And in the field of construction planning management is no exception. The application of GIS in the world has been studied and applied extensively. The effectiveness of GIS research and application is enormous.

Some GIS applications related to urban planning and construction development such as:

$\square$ Anthony Yeh created application "Office Automation with GIS in Urban Planning and Management". The system was developed by CB Richard Ellis, Center for Urban and Environmental Planning, University of Hong Kong's Research Institute, based on the ArcView platform. The system was developed to serve the management of urban planning. Author has designed the program capable of automatically analyzing the information from the GIS database according to the specific criteria of the user. Input of spatial data can be in the form of Vector or Raster. Database and system are built to analyze, query and update geographic data.

$\square$ Stephen Pauleit and Friedrich Duhme created "GIS Assessment of Munich's Urban Forest Structure for Urban Planning". This is a GIS application developed and applied to manage the impact assessment of the spatial structure of forests as well as their impact on the living environment of the German city of Munich. Present urban planning. The application enables users to obtain information on the density, size, age of vegetation in the forests and the impact of urbanization on the living environment of plant and animal species. The constructed GIS model helps to evaluate the urban spatial model of urban forests closely linked to land use planning and construction development.

\subsection{Study area}

The research area is Ho Chi Minh City, a vital area of the South both economically and politically. Including District 2, Ho Chi Minh City as the focus of the topic.

Within the scope of the topic, the research will focus on how developed GIS applications can meet the requirements of the management of zoning information in the following areas:

$\square$ Management of functional use for each site (location, boundary, nature and size of functional areas in the planning area, density of construction, land use coefficient and dimension maximum height, minimum, foundation; red line boundaries, construction boundaries)

Management of land use information of functional areas;

Manage the layout of social infrastructure;

Summarize statistical indicators.

\subsection{Research Methods}

Thesis paper is implemented with the following methods:

$\square$ collection, analysis and synthesis:

Collecting, analyzing and synthesizing related legal documents and documents

Planning data and planning information management process of the state management units

Analysis method, system design:

- Analysis, selection of application software technology, database management system and GIS technology

- Analysis of professional process of planning information management division functional district

- Design GIS database management information planning zoning function

- Analyze the design of the GIS application information management module planning subdivision function 


\subsection{Result}

Description of module overall functionality is shown in the schema in figure 5 [8].

Within this study data transformation was performed using ArcGIS ArcCatalog to transform the XML data model into geodatabase data. Next, use the ArcToolBox tool to transfer CAD data (* .dwg, * .dgn) data to the geodatabase. The modules of Application are programmed using VBA integrated in ArcGIS.

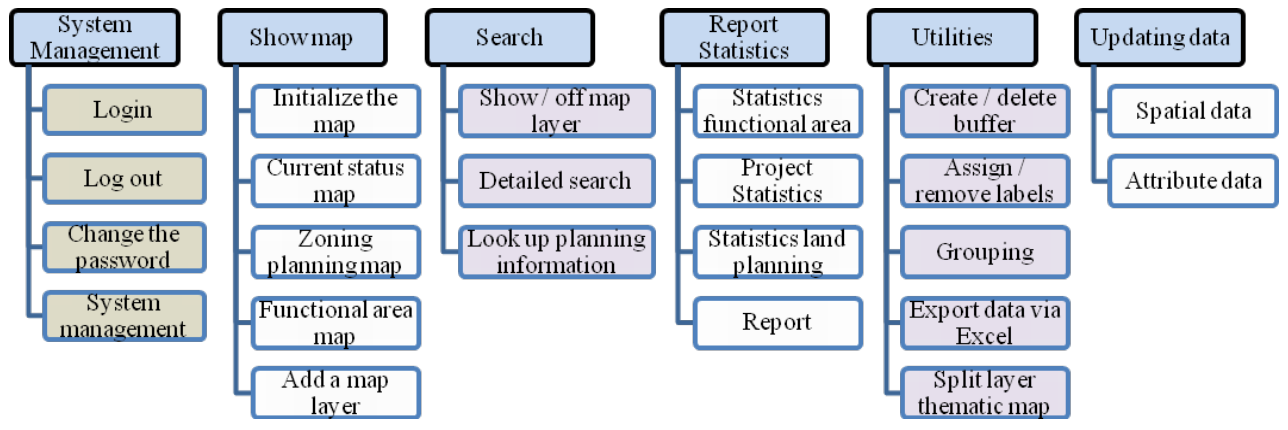

Fig. 5. Schema of functional modules of the application.

The interface of the application in Vietnamese is shown in Figure 6.

A in Figure 7 shown result extract map of groupping zoning function [10,11].

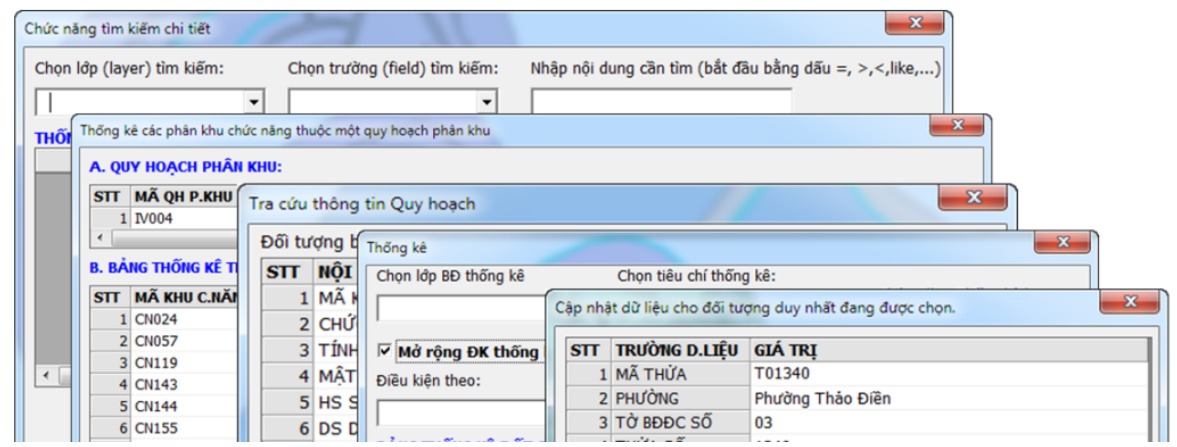

Fig. 6. The interface of the application in Vietnamese.

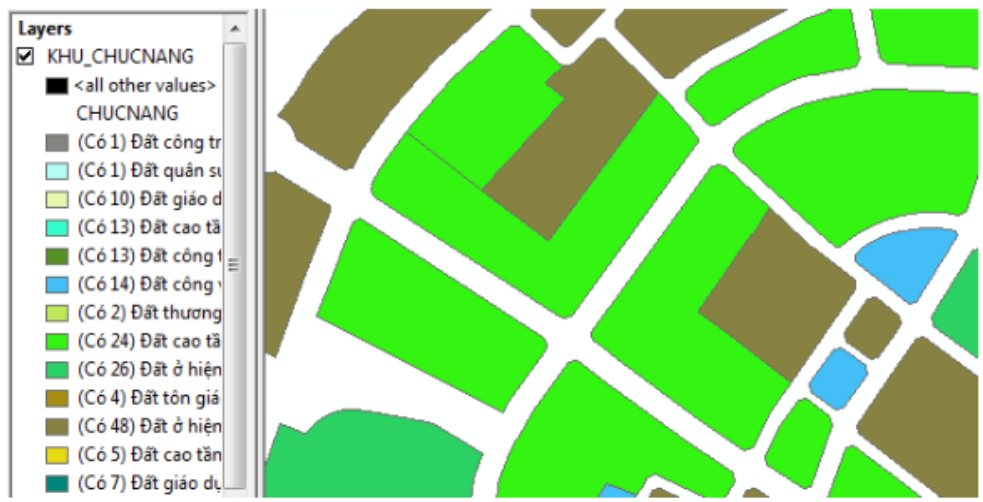

Fig. 7. Result extract map of groupping zoning function. 
From the test result's module functions, shows:

- The search for planning information or information of some object on

The map can be easily implemented. Search results will be full information

Enough about the search object, this information can be exported / printed.

Besides, the statistics and aggregation of all kinds of land can also be easily and quickly implemented easily and accurately.

- Make reports and print search results, aggregate statistics.

- This result is the basis to help the management agency can actually

It is fast and effective in providing planning information, granting planning certificates and managing construction planning.

\section{Conclusions}

- Gather information, documents and opinions of the managers of some districts in Ho Chi Minh City from which to propose the model of application of GIS technology to the management of information of planning.

- Research and analysis of effective documents issued by state authorities on planning and management planning; From this, a functional model of functional information management plan for the functional area planning under the scope and management functions of the district is proposed $[12,13]$.

- Analyze the design of geographic information database for the management of functional planning information.

- Building application module to support management information planning functional zones in the district.

Practical significance

- Application modules allow planning management departments in urban management departments to synthesize, consult planning information, contribute to minimize management time, provide Granted planning information is promptly prompt.

The process of establishing a 3D map of floodplain partitioning can be done in real time according to hydrological forecasts for people, leaders, flood prevention and rescue agencies. ... to know and avoid, mitigate the impact, as well as choose the route when joining traffic. The base map layers need not be established continuously, only updated when there is a change in the field, while the wetland map layer can be updated daily, or hours as the flood level changes on the real data measurements and forecasts of hydrological agencies. This map should be published online on the Internet so that people (now almost everyone uses Smartphone, Table, Google Map, 3D service ...) can refer to and visualize the color, be visual.

\section{References}

1. http: // www.ncfloodmaps.com

2. http://apps.environment-agency.gov.uk

3. http://vnsc.org.vn/en/news/Ung-dung-Cong-nghe-Vu-tru/Philippines-xay-dung-ban-dolu-lut-3D-264/

4. http://quangnam.kttvttb.vn/

5. http://www.baomoi.com/Binh-Dinh- Lap-ban-do-ngap-lut / 144 / 14254581.epi

6. A. T. Nguyen, GIS Conference-2014, 706 -712 (2014)

7. http://www.phongchonglutbaotphem.gov.vn/?id=44\&cid=2672

8. Dao Huu Si, Master thesis (Ho Chi Minh City, 2011) 
9. A. T. Nguyen, Create $3 \mathrm{~d}$ model of earth terrain from $2 \mathrm{~d}$ map, GIS Conference -2015 , Viet Nam (2015)

10. A. T. Nguyen, Geodesy and cartography-Moscow 8, 38-41 (2015)

11. A. T. Nguyen, Certificate of state registration of computer programs 2015611862, CoordinatGrid (Siberian State Geodesic Academy (RU), 2015) 